\title{
Metabolism of Puerarin and Daidzin by Human Intestinal Bacteria and Their Relation to in Vitro Cytotoxicity
}

\author{
Dong-Hyun KIM, ${ }^{*, a}$ Ki-Ung Yu, ${ }^{a}$ Eun-Ah BAE, ${ }^{b}$ and Myung Joo HAN ${ }^{b}$ \\ College of Pharmacy, ${ }^{a}$ and Department of Food and Nutrition, ${ }^{b}$ Kyung-Hee University, \#l Hoegi, Dongdaemun-ku, Seoul \\ 130-701, Korea. Received November 14, 1997; accepted March 3, 1998
}

\begin{abstract}
When puerarin or daidzin were incubated for $24 \mathrm{~h}$ with human intestinal bacteria, two metabolites, daidzein and calycosin, were produced from them, respectively. The metabolic time course of puerarin was as follows: at an early time, puerarin was converted to daidzin, and then calycosin. The metabolic time course of daidzin by human intestinal bacteria was also similar to that of puerarin. The in vitro cytotoxicities of these metabolites, calycosin and daidzein, were superior to those of puerarin and daidzein.
\end{abstract}

Key words Bacteroides spp.; puerarin; daidzin; calycosin; intestinal bacteria; cytotoxicity

Most herbal medicines are orally administered as decoctions. The components of these herbal medicines are therefore inevitably brought into contact with intestinal microflora in the alimentary tract. Most components may be transformed by the intestinal bacteria before absorption from the gastrointestinal tract. Studies on the metabolism of the components by human intestinal microflora are of a great importance to an understanding of their biological effects. ${ }^{1,2}$

Among herbal medicines, Puerariae Radix is frequently used in the traditional clinic. It is one of the most important crude drugs in Oriental medicine. ${ }^{3)}$ There have been many reports on its constituents and pharmacological activities. Some isoflavones, puerarin, daidzein and daidzin, were isolated as the main component of Puerariae lobata (Leguminosase). ${ }^{4,5}$ Among them, daidzin has acetaldehyde dehydrogenase and cAMP phosphodiesterase inhibitory and antispasmatic activities, ${ }^{6,7)}$ and puerarin has hypoglycemic and coronary artery blood flow increasing activities. ${ }^{8}$

In addition, Yasuda et al. investigated the urinary and biliary excretion of the metabolites of puerarin and daidzin., ${ }^{9,10)}$ When puerarin was orally administered to rats, puerarin and four conjugates of daidzein were isolated from the urine. When daidzin was orally administered to rats, four conjugates of daidzein, not daidain, were isolated from the urine. Based on these results, we thought that these compounds could be metabolized to their aglycons by rat intestinal bacteria before being absorbed into the blood. However, the metabolism of these compounds by human intestinal bacteria was not studied. The present paper investigated the metabolism of puerarin and daidzin by human intestinal bacteria and the in vitro cytotoxicity of their metabolites against tumor cell lines.

\section{MATERIALS AND METHODS}

Materials Puerarin and daidzein were purchased from Sigma Chem. Co. (U.S.A.). Daidzin was prepared according to the method of Hayakawa et al. ${ }^{11)}$ General anaerobic medium (GAM) and glucose blood liver medium (BL) were purchased from Nissui Pharmaceutical Co., Ltd. The other media were purchased from Difco Co. (U.S.A.). Tumor cell lines were purchased from the Korean Cell Line Bank (Seoul National University, Korea).

Instruments Melting points were determined on an electrothermal digital melting point apparatus. ${ }^{1} \mathrm{H}-$ and ${ }^{13} \mathrm{C}$ NMR spectra were taken on a Brucker-AMX 500 spectrometer with tetramethylsilane (TMS) as an internal standard. Electron impact-mass spectra (EI-MS) was taken on high resolution mass spectra (HRMS).

Metabolites To isolate the metabolites of puerarin or daidzin by human intestinal bacteria, a reaction mixture containing $0.4 \mathrm{~mm}$ puerarin (or daidzin) and $0.5 \mathrm{~g}$ fresh human fecal bacteria in a final volume of $50 \mathrm{ml}$ of an anaerobic dilution medium was incubated at $37^{\circ} \mathrm{C}$ for $20 \mathrm{~h}$. The reaction mixture was extracted three times with $5 \mathrm{ml}$ of ethylacetate. The ethylacetate extract was applied to silica gel column chromatography $(1.5 \times 20 \mathrm{~cm})$ with $\mathrm{CHCl}_{3} / \mathrm{MeOH}(9: 1)$. The isolated metabolites were crystallized with $\mathrm{MeOH}$.

Daidzein: Colorless needles from $\mathrm{MeOH}, \mathrm{mp} 316-$ $318^{\circ} \mathrm{C}$ (dec.). IR $(\mathrm{KBr}) \mathrm{cm}^{-1}: 3215(\mathrm{OH}), 1615$ (conjugated $\mathrm{C}=\mathrm{O}$ ), 1518 (arom. $\mathrm{C}=\mathrm{C}$ ). EI-MS $m / z: 254\left(\mathrm{M}^{+}\right) .{ }^{1} \mathrm{H}-(500$ $\left.\mathrm{MHz}, \mathrm{CD}_{3} \mathrm{OD}\right) \delta: 8.13(1 \mathrm{H}, \mathrm{s}, \mathrm{H}-2), 8.04(1 \mathrm{H}, \mathrm{d}, J=8.9 \mathrm{~Hz}$, $\mathrm{H}-5), 6.92(1 \mathrm{H}, \mathrm{dd}, J=8.9,2.0 \mathrm{~Hz}, \mathrm{H}-6), 6.84(1 \mathrm{H}, \mathrm{d}$, $J=2.0 \mathrm{~Hz}, \mathrm{H}-8), 7.35\left(1 \mathrm{H}, \mathrm{d}, J=9.0 \mathrm{~Hz}, \mathrm{H}-2^{\prime}\right), 6.81(1 \mathrm{H}, \mathrm{d}$, $\left.J=9.0 \mathrm{~Hz}, \mathrm{H}-3^{\prime}\right), 6.84\left(1 \mathrm{H}, \mathrm{d}, J=9.0 \mathrm{~Hz}, \mathrm{H}-5^{\prime}\right), 7.35(1 \mathrm{H}, \mathrm{d}$, $\left.J=9.0 \mathrm{~Hz}, \mathrm{H}-6^{\prime}\right) .{ }^{13} \mathrm{C}-\mathrm{NMR}\left(125 \mathrm{MHz}, \mathrm{CD}_{3} \mathrm{OD}\right) \delta: 155.0(\mathrm{C}-$ 2), 126.25 (C-3), 178.10 (C-4), 128.31 (C-5), 116.27 (C-6), 162.98 (C-7), 105.00 (C-8), $158.79(\mathrm{C}-9), 117.05$ (C-10), $124.11\left(\mathrm{C}-1^{\prime}\right), 131.41\left(\mathrm{C}-2^{\prime}\right), 115.85\left(\mathrm{C}-3^{\prime}\right), 159.25(\mathrm{C}-4)$, $115.80(\mathrm{C}-5), 131.41(\mathrm{C}-6)$.

Calycosin: White amorphous powder from $\mathrm{MeOH}, \mathrm{mp}$ $250-252^{\circ} \mathrm{C}$ (dec.). IR (KBr) cm ${ }^{-1}: 3241(\mathrm{OH}), 1628$ (conjugated $\mathrm{C}=\mathrm{O}$ ), 1510 (arom. $\mathrm{C}=\mathrm{C}$ ). EI-MS $\mathrm{m} / z: 284\left(\mathrm{M}^{+}\right)$. ${ }^{1} \mathrm{H}-\left(500 \mathrm{MHz}, \mathrm{CD}_{3} \mathrm{OD}\right) \delta: 8.16(1 \mathrm{H}, \mathrm{s}, \mathrm{H}-2), 8.05(1 \mathrm{H}, \mathrm{d}$, $J=8.9 \mathrm{~Hz}, \mathrm{H}-5), 6.93(1 \mathrm{H}, \mathrm{dd}, J=8.9,2.3 \mathrm{~Hz}, \mathrm{H}-6), 6.85(1 \mathrm{H}$, d, $J=2.3 \mathrm{~Hz}, \mathrm{H}-8), 7.15\left(1 \mathrm{H}, \mathrm{d}, J=2.0 \mathrm{~Hz}, \mathrm{H}-2^{\prime}\right), 6.48(1 \mathrm{H}, \mathrm{d}$, $\left.J=8.2 \mathrm{~Hz}, \mathrm{H}-5^{\prime}\right), 6.95\left(1 \mathrm{H}, \mathrm{dd}, J=8.2,2.0 \mathrm{~Hz}, \mathrm{H}-6^{\prime}\right), 3.89$ $\left(3 \mathrm{H}, \mathrm{s}, \mathrm{OCH}_{3}\right) .{ }^{13} \mathrm{C}-\mathrm{NMR}\left(125 \mathrm{MHz}, \mathrm{CD}_{3} \mathrm{OD}\right) \delta: 147.9(\mathrm{C}-$ 2), 124.8 (C-3), 178.2 (C-4), 126.0 (C-5), 116.2 (C-6), 164.8 (C-7), 103.2 (C-8), 159.8 (C-9), 116.5 (C-10), 122.9 (C-1'), $118.1\left(\mathrm{C}-2^{\prime}\right), 154.7(\mathrm{C}-3), 148.8(\mathrm{C}-4), 114.1(\mathrm{C}-5), 128.5$ (C-6), $56.41\left(\mathrm{OCH}_{3}\right)$.

Thin Layer Chromatography (TLC) TLC for puerarin, daidzin, daidzein and calycosin were performed on silica gel plates (Merck, silica gel 60F-254) as follows: developing solvents system, $\mathrm{CHCl}_{3} /$ methanol $(4: 1)$. The quantity of these compounds were assayed with a TLC scanner (Shimadzu CS-920).

(C) 1998 Pharmaceutical Society of Japan 

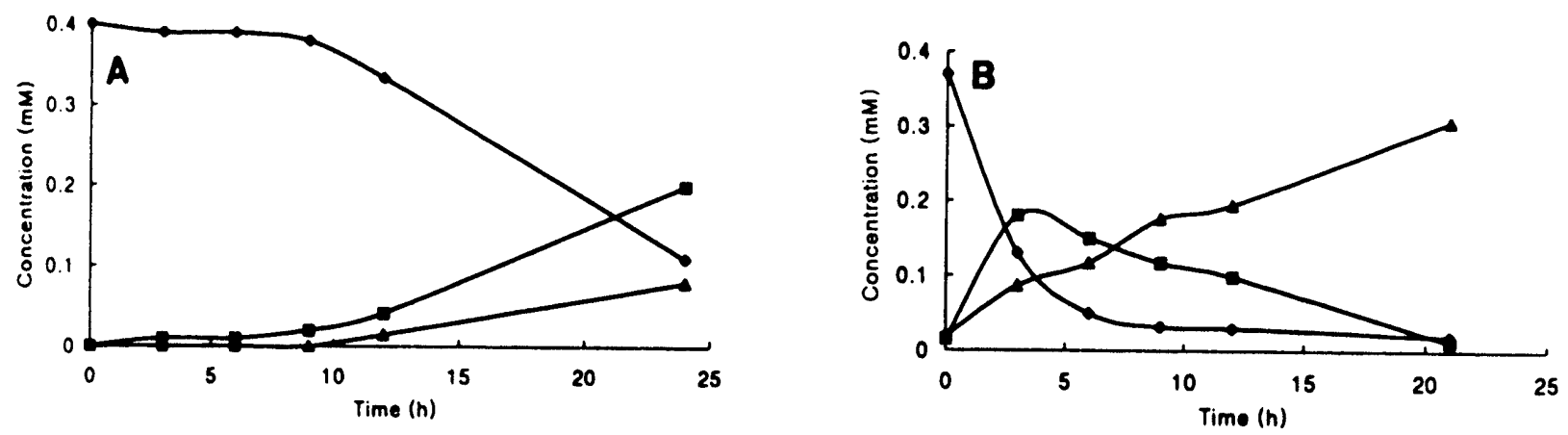

Fig. 1. Time Course of Metabolism of Puerarin (A) and Daidzin (B) by Human Intestinal Bacteria

(A): $\bullet$, puerarin; $\mathbf{\square}$, daidzein; $\mathbf{\Lambda}$, calycosin. (B): $\bullet$, daidzin; $\mathbf{\square}$, daidzein; $\mathbf{\Lambda}$, calycosin.

Time Courses of Metabolism of Puerarin and Daidzin by Intestinal Bacteria Puerarin and daidzin metabolizing activities were measured as follows. First, the assay mixture contained $0.4 \mathrm{~mm}$ puerarin (or daidzin) and $0.5 \mathrm{~g}$ fresh human fecal bacteria in a final volume of $50 \mathrm{ml}$ of an anaerobic dilution medium. The mixture was incubated at $37^{\circ} \mathrm{C}$ for $1 \mathrm{~d}$ and an aliquot $(2.5 \mathrm{ml})$ of the reaction mixture was periodically extracted twice with $10 \mathrm{ml}$ of ethylacetate. The ethylacetate fraction was analyzed by TLC.

Second, $5 \mathrm{ml}$ of the 10 -fold diluted fresh human fecal suspension or the isolated bacteria which was previously cultured was inoculated into $45 \mathrm{ml}$ of GAM broth containing $0.4 \mathrm{~mm}$ puerarin (or daidzin) and was then incubated at $37^{\circ} \mathrm{C}$ for $1 \mathrm{~d}$, and an aliquot $(2 \mathrm{ml})$ of the reaction mixture was periodically extracted twice with $5 \mathrm{ml}$ of ethylacetate. The ethylacetate fraction was analyzed by TLC.

Isolation of Intestinal Bacteria Metabolizing Puerarin A suspension of the fresh feces of a Korean man was diluted $10^{5}$ to $10^{8}$-fold with the GAM medium. An aliquot $(200 \mu \mathrm{l})$ of the $10^{7}$-diluted human feces was inoculated onto a $\mathrm{BL}$ agar plate, and was then anaerobically incubated at $37^{\circ} \mathrm{C}$ for $4 \mathrm{~d}$. Each colony was incubated in $5 \mathrm{ml}$ of GAM broth containing $0.2 \mathrm{~mm}$ puerarin (or daidzin). The cultured media were extracted with $5 \mathrm{ml}$ of ethylacetate. After evaporation, each ethylacetate fraction was analyzed for puerarin (or daidzin), daidzein and calycosin by TLC. Among the tested bacteria, Y-10 has the most puerarin metabolizing activity and K-111 has the most daidzin metabolizing activity. Identification of these isolated bacteria was performed according to Bergey's manual. ${ }^{12)} \mathrm{Y}-10$, which was a gram-positive, $\beta$-glucosidase-positive, $\alpha$-rhamnosidase-negative, methyl red testnegative and anaerobic coccus, was Peptostreptococcus spp., and $\mathrm{K}-111$, which was a gram-positive, $\beta$-glucosidase-positive, $\alpha$-rhamnosidase-negative, methyl red test-positive and anaerobic rod, was Bifidobacterium spp.

In Vitro Cytotoxicity Assay The in vitro cytotoxicity assay was performed according to the method of Carmichael et al. ${ }^{13)}$

\section{RESULTS AND DISCUSSION}

Metabolites of Puerarin and Daidzin by Human Intestinal Bacteria To investigate the metabolites of puerarin by human intestinal bacteria, puerarin was anaerobically incubated for $12 \mathrm{~h}$ with a bacterial mixture from human feces. Then, the metabolites were extracted with ethylacetate, separated by silica gel column chromatography, and analyzed by
TLC, ${ }^{13} \mathrm{C}$ - and ${ }^{1} \mathrm{H}-\mathrm{NMR}$ and EI-MS.

Two metabolites (M1 and M2) were observed by TLC. These metabolites exhibited absorption due to a hydroxyl $\left(3215-3241 \mathrm{~cm}^{-1}\right)$, conjugated carbonyl (1615-1628 $\left.\mathrm{cm}^{-1}\right)$ and aromatic function $\left(1510-1518 \mathrm{~cm}^{-1}\right)$ in the IR spectra and showed maximal absorptions at $247-250 \mathrm{~nm}$ in the ultraviolet (UV) spectra. The $R f$ of metabolite M1 was 0.59 on TLC (developing solvent system in Materials and Methods). EI-MS of M1 showed a molecular ion peak at $\mathrm{m} / \mathrm{z}$ $254\left(\mathrm{M}^{+}\right)$. TLC chromatogram and ${ }^{1} \mathrm{H}$ - and ${ }^{13} \mathrm{C}-\mathrm{NMR}$ spectra of M1 showed that the isoflavone skeleton of puerarin was intact but a glucosyl moiety was missing. Compared with an authentic compound, M1 was daidzein. The $R f$ of metabolite M2 was 0.63 on TLC (developing solvent system in Materials and Methods). The TLC chromatogram and ${ }^{1} \mathrm{H}$ - and ${ }^{13} \mathrm{C}$ NMR spectra of M2 showed that the isoflavone skeleton of puerarin was modified by a hydroxyl group and a methyl group, but a glucosyl moiety was missing. EI-MS of M2 showed a molecular ion peak at $m / z 284\left(\mathrm{M}^{+}\right)$. By these results, M2 was calycosin, which was first isolated from Trifolium pratense (Leguminosae). ${ }^{14)}$

To compare the metabolites of daidzin with those of puerarin by human intestinal bacteria, daidzin or puerarin were anaerobically incubated for $12 \mathrm{~h}$ with a bacterial mixture of fresh human feces. Two metabolites, daidzein and calycosin, were also separated by means of silica gel column chromatography. The pattern of these metabolites was similar to those of the metabolites of puerarin, although the metabolic rate of daidzin was faster than that of puerarin.

The Time Course of Metabolism of Puerarin and Daidzin by Human Intestinal Bacteria The time course of transformation of puerarin and daidzin by human intestinal bacteria was shown in Fig. 1. Puerarin started to be converted to daidzein. Daidzein was slowly increased according to the lapse of incubation time. The major metabolite was daidzein for $24 \mathrm{~h}$ incubation with the bacterial mixture. Daidzin also started to be converted to daidzein. The major metabolite was daidzein and the minor metabolite was caly$\operatorname{cosin}$ for $6 \mathrm{~h}$ incubation of the reaction mixture. However, calycosin was the main metabolite after $9 \mathrm{~h}$ incubation of daidizin with the bacterial mixture.

When puerarin or daidzin were anaerobically incubated with fresh human fecal suspension in GAM broth, puerarin or daidzin were mainly transformed to daidzein according to the growth of human intestinal microflora, then daidzein was transformed to calycosin. The biotransformation of daidzin to daidzein proceeded more easily than that of puerarin to 
<smiles>O=c1c(-c2ccc(O)cc2)coc2c(Cl)c(O)ccc12</smiles><smiles>COc1ccc2c(=O)c(-c3ccc(O)cc3)coc2c1</smiles>

$\searrow$
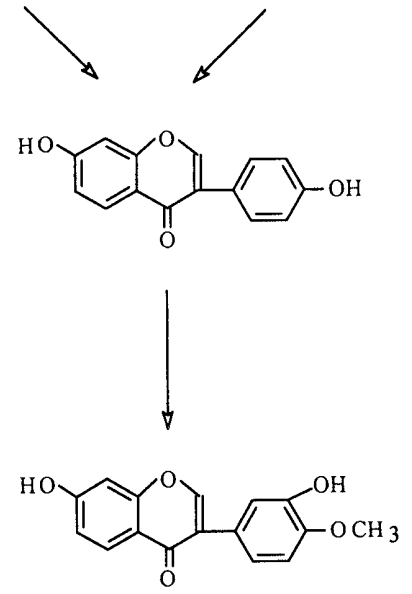

Chart 1. Proposed Metabolic Pathway of Puerarin and Daidzin by Human Intestinal Bacteria

daidzein. The metabolic pathway of puerarin by Y-10, which was the gram-negative Peptostreptococcus spp. isolated from human intestinal microflora, and that of daidzin by K-111, which was the gram-positive Bifidobacterium spp. isolated from human intestinal microflora, were similar to those of puerarin and daidzin by human intestinal bacteria, respectively. Thus, the enzyme activity of human intestinal microflora which hydrolyze puerarin to daidzein, C-glycosidase, was more potent than those which hydrolyze daidzin to daidzein.

In addition, Yasuda et al. investigated the activity of the metabolites on the urine and bile of rats orally administered puerarin and daidzin., ${ }^{9,10}$ They could identify only glucuronide and sulfate conjugates of daidzein as main metabolites. In the present study, these were also metabolized to daidzein by human intestinal bacteria, and daidzin was more easily metabolized than puerarin. Thus, these results agreed with the study of Yasuda et al. ${ }^{9,10)}$

We insist that puerarin and daidzin could be transformed to daidzein and calycosin in the intestine by human intestinal bacteria (Chart 1), and these metabolic processes are important in the pharmacological effect of these compounds.

In Vitro Cytotoxicity of Metabolites against Tumor Cell Lines When puerarin or daidzin were metabolized to daidzein and calycosin by human intestinal bacteria, the in vitro cytotoxicity on tumor cell lines was assayed (Table 1). The metabolites, daidzein and calycosin, showed potent cyto-
Table 1. In Vitro Cytotoxicity of Daidzin, Puerarin and Their Metabolites against Tumor Cell Lines

\begin{tabular}{lcccc}
\hline \multirow{2}{*}{ Compound } & \multicolumn{4}{c}{$\mathrm{ED}_{50}(\mathrm{~mm})$} \\
\cline { 2 - 5 } & $\mathrm{P} 388^{a)}$ & $\mathrm{SNU} \mathrm{C}^{b)}$ & $\mathrm{A} 549^{c)}$ & ZR-75-1 $^{d)}$ \\
\hline Puerarin & $>2$ & $>2$ & $>2$ & $>2$ \\
Daidzin & $>2$ & $>2$ & $>2$ & $>2$ \\
Daidzein & 0.82 & 0.97 & 1.72 & $>2$ \\
Calycosin & 0.46 & 0.50 & 0.64 & 0.73 \\
Adriamycin & 0.003 & 0.05 & 0.1 & 0.02 \\
\hline
\end{tabular}

a) Mouse lymphoid neoplasma cell line. b) Human colon cancer cell line. c) Human lung cancer cell line. $d$ ) Human breast cancer cell line.

toxicity against tumor cell lines. The $\mathrm{ED}_{50}$ values of daidzein and calycosin were $0.82-1.72$ and $0.46-0.73 \mathrm{~mm}$, respectively. However, daidzin and puerarin were not active. We found that the cytotoxicity was increased when isoflavone glycosides were metabolized to their aglycones by human intestinal microflora. These results suggested that natural glycosides are prodrugs which can be transformed to active compounds by intestinal microflora.

Acknowledgement We thank Dr. In-Jong Kim and Ms. Hae-Young Park for technical assistance. This work was supported by a grant from KOSEF (971-0711-094-2).

\section{REFERENCES}

1) Kim D.-H., Jang. I.-S., Kim N.-J., Youn W.-G., Yakhak Hoeji, 38, 286-292 (1994).

2) Kobashi K., Akao T., Bioscience Microflora, 16, 1-7 (1997).

3) Hara M., Modern Oriental Medicines (現代東洋醫學), 3, 42-53 (1982).

4) Shibata S., Murakami T., Nishikawa Y., Yakugaku Zasshi, 79, 757760 (1959).

5) Murakami T., Nishikawa Y., Ando T., Chem. Pharm. Bull., 8, 688692 (1960).

6) Keung W. M., Valee B. L., Proc. Natl. Acad. Sci. U.S.A., 90, 12471251 (1993).

7) Nikaido T., Ohmoto T., Sankawa U., Hamanaka T., Totsuka K., Planta Med., 46, 162-165 (1982).

8) Shen Z.-F., Xie M.-Z., Acta Pharm. Sin., 20, 863-866 (1985).

9) Yasuda T., Kano Y., Saito K., Ohsawa K., Biol. Pharm. Bull., 17, $1369-1374$ (1994).

10) Yasuda T., Kano Y., Saito K., Ohsawa K., Biol. Pharm. Bull., 18, $300-303$ (1995).

11) Hayakawa J., Noda N., Yamada S., Uno K., Yakugaku Zasshi, 194, $50-56$ (1984).

12) Kreig N. R., Holt J. G. (ed), "Bergey's Manual of Systemic Bacteriology" Williams and Wilkins, Baltimore, 1984.

13) Carmichael J., DeGreff W. G., Gazdar A. F., Minna J. D., Mitchell J. B., Cancer Res., 47, 936-940 (1987).

14) Biggs D. R., Lane G. A., Phytochemistry, 17, 1683-1684 (1978). 